\title{
PREDIKSI LABA PENJUALAN MENGGUNAKAN METODE ALGORITMA C4.5 PADA PT.BASUNJAYA NASTARI
}

\author{
Ilman Kadori' ${ }^{1}$, Bei Harira Irawan², Mustamil $^{3}$ \\ 1,2,3STMIC MIC Cikarang \\ Cikarang Bekasi, Indonesia \\ ilmankadori@gmail.com - beiharira@gmail.com-mustamil25@gmail.com
}

\begin{abstract}
Abstrak
Era komputerasi saat ini membawa dampak dalam banyaknya data penjualan oleh sebab itu dibutuhkan sebuah metode perhitungan laba penjualan yang efisien dan tepat untuk bisa selalu bertahan dalam ketatnya persaingan. Masalah yang dialami PT. Basunjaya Nastari sebagai perusahaan yang bergerak dibidang penyedia jasa dan jual beli bahan kimia adalah menentukan keuntungan penjualan barang untuk customer mana yang memiliki performasi, baik kualitas dan kuantitas, sehingga perusahaan bisa memprioritaskan customer tersebut dalam memenuhi permintaan yang dibutuhkan. Metode teknik klasifikasi dan prediksi data mining digunakan dalam memecahkan masalah tersebut yaitu Decision Tree. Teknik ini banyak digunakan karena dapat menyajikan data prediksi penjualan yang lebih cepat. Evaluasi hasil klasifikasi dalam prediksi keuntungan memiliki tingkat akurasi sebesar $81,71 \%$ dari data training dan tingkat akurasi sebesar $85,83 \%$ dari data testing dengan Confusion Matrix. Jika dilihat dengan kurva ROC menggunakan data training dengan akurasi Excellent Classification sebesar 1,000 dan data testing dengan akurasi Excellent Classificationsebesar 0,925 .
\end{abstract}

Kata kunci: prediksi laba, keuntungan penjualan, decision tree, algoritma C4.5

\begin{abstract}
In the current era of computerization has an impact on the amount of sales data, therefore we need an efficient and precise method of calculating sales profits to be able to always survive the intense competition. Problems experienced by PT. Basunjaya Nastari as a company engaged in providing services and buying and selling chemicals is to determine the advantages of selling goods to customers who have performance, both in quality and quantity, so that the company can prioritize these customers in meeting the required demands, classification techniques and data prediction methods. mining is used to solve this problem, the Decision Tree. This technique is widely used because it can provide faster sales prediction data. Evaluation of the classification results in profit prediction has an accuracy rate of $81.71 \%$ of the training data and an accuracy rate of $85.83 \%$ of the testing data with the Confusion Matrix. If you look at the ROC curve using training data with an accuracy of Excellent Classification of 1,000 and testing data with an accuracy of Excellent Classification of 0.925 .
\end{abstract}

Keywords: profit prediction, sales profit, decision tree, $C 4.5$ algorithm 


\section{PENDAHULUAN}

PT. Basunjaya Nastari merupakan perusahaan yang bergerak di bidang penyedia jasa Waste Water Treatment dan jual beli bahan kimia yang terletak di daerah kawasan industri Cikarang Jawa Barat. Perusahaan ini memiliki beberapa customer yang antara lain juga perusahaanperusahaan besar di kawasan industri. Masalah yang dialami PT Basunjaya Nastari adalah menentukan keuntungan penjualan barang untuk customer mana yang memiliki performasi, baik kualitas dan kuantitas, sehingga perusahaan bisa memprioritaskan customer tersebut dalam memenuhi permintaan yang dibutuhkan. Data penjualan yang ada belum diolah secara optimal untuk dijadikan referensi mencari performasi customer unggul guna meningkatkan penjualan lebih optimal. Belum adanya suatu metode yang tepat dan efisien dalam menentukan prediksi penjualan yang didapat dari hasil penjualan kepada customer.

Penelitian yang dilakukan oleh Rika Nofitri dan Muhammad Ardiansyah Sembiring (2017) yang membahas tentang analisa kinerja algoritma C4.5 dalam memprediksi pencapaian profit untuk menemukan new knowledge (pengetahuan baru) berupa rule dalam memprediksi pencapaian profit. Proses penelitian ini menghasilkan 6 buah rule sebagai landasan dalam memprediksi pencapaian profit dengan tingkat akurasi sebesar $92,60 \%+/-$ $1,36 \%$.

Penelitian lain oleh Sandrawira Anggraini dkk (2018) tentang optimalisasi transaksi penjualan ban, memiliki pengaruh pada penentuan persediaan ban di gudang CV Roda Inti Mas. Dari penelitian ini jumlah persediaan ban dapat diatur dengan baik, sehingga tidak lagi terjadi kekurangan ataupun kelebihan stok. Hal ini membantu dalam pengaturan optimalisasi transaksi ban.

Penelitian lain oleh Goldie Gunadi dan Dana Indra Sensuse (2012) tentang penerapan metode data mining Market Basket Analysis terhadap data penjualan produk buku dengan menggunakan algoritma apriori dan frequent pattern growth (fp-growth) pada percetakan PT Gramedia. Penelitian dilakukan dengan mencari sejumlah frequent itemset dan dilanjutkan dengan pembentukan aturanaturan asosiasi (association rules). Simpulan didapatkan bahwa tingkat kekuatan aturan-aturan asosiasi yang dihasilkan oleh algoritma Apriori lebih besar dibandingkan dengan yang dihasilkan oleh algoritma FP-growth. Hal ini disebabkan oleh rendahnya nilai support yang menggambarkan terjadinya kombinasi items dalam aturan terhadap keseluruhan data transaksi terkini penjualan produk buku. Tingkat akurasi dari algoritma Apriori terhadap FP-growth adalah sebesar $257,4543 \%$.

Penelitian lain oleh E. Buulolo, N. Silalahi, F. F and R. Rahim (2017) tentang prediksi dampak gempa bumi menggunakan algoritma C4.5. Hasil penelitian menunjukkan bahwa algoritma C4.5 dapat memprediksi dampak gempa berdasarkan data seismik yang pernah terjadi dimana dampak gempa dipengaruhi oleh beberapa karakteristik atau kondisi gempa yaitu skala, durasi, jarak dari pantai dan pusat gempa.

\section{METODE PENELITIAN}

Pengumpulan data dilakukan langsung di PT. Basunjaya Nastari. Data yang telah terkumpul berjumlah 192. Data 
kemudian dibagi menjadi 2 yaitu data training sejumlah 154 data dan data testing sejumlah 38 data dengan perbandingan $80 \%$ dan $20 \%$. Hasil data training digunakan untuk memperoleh hasil laba penjualan dalam bentuk pohon keputusan. Sedangkan data testing digunakan untuk mengukur tingkat akurasi dari hasil klasifikasi tersebut. Kerangka pemikiran yang digunakan pada penelitian ini ditunjukkan pada Gambar 1.

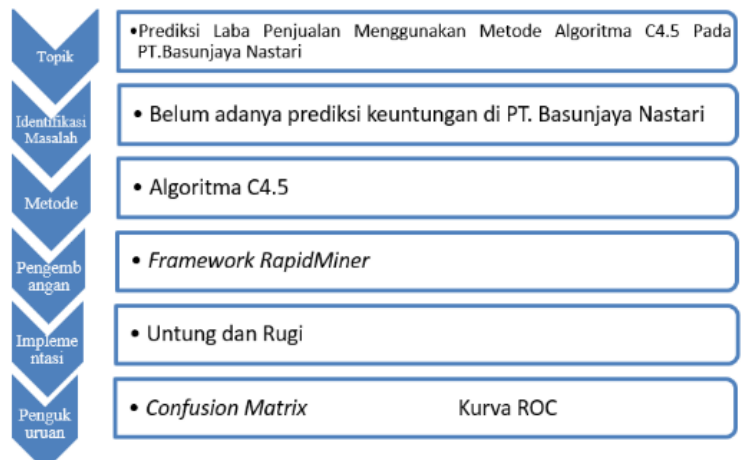

Gambar 1. Kerangka Pemikiran

\section{HASIL DAN PEMBAHASAN}

Tabel 1 menunjukkan kategori penjualan pada PT. Basunjaya Nastari dari proses klasifikasi Knowledge Discovery in Databases (KDD).

Tabel 1. Tabel Kategori Penjualan

\begin{tabular}{|c|c|c|c|c|c|c|c|c|}
\hline Baraug & Waraa Baraug & Variasi Baraug & Jenis Barang & Kemasau & Satuan & Harga & Customer & Kelas \\
\hline & Coklat & $\mathrm{Ya}_{\mathrm{a}}$ & Padat & Pcs & Lt & \begin{tabular}{|l} 
Rendath \\
\end{tabular} & PT. YKK Z Zpco & Rugi \\
\hline & Putith & Tidak & Caif & Zack & $\mathrm{K}_{8}$ & Sedang & PT.JWP & Untung \\
\hline 3 & Abu-Abu & & & Jerican & & \begin{tabular}{|l|l|} 
Tinggi \\
\end{tabular} & PT. Deaso & \\
\hline 4 & Kning & & & Tangli & & & PT. Suttek & \\
\hline 5 & Heatan & & & & & & PT.RTT & \\
\hline 6 & Biru & & & & & & PT. Yomanasti & \\
\hline & & & & & & & PT.MUI & \\
\hline & Menal & & & & & & PT. Sugity & \\
\hline 9 & & & & & & & PT. Masais & \\
\hline
\end{tabular}

Hasilnya kemudian dikategorikan dengan variabel, atribut dengan nilai Rugi dan Untung yang kemudian dijadikan data training dan data testing.
Tabel 2. Data Training

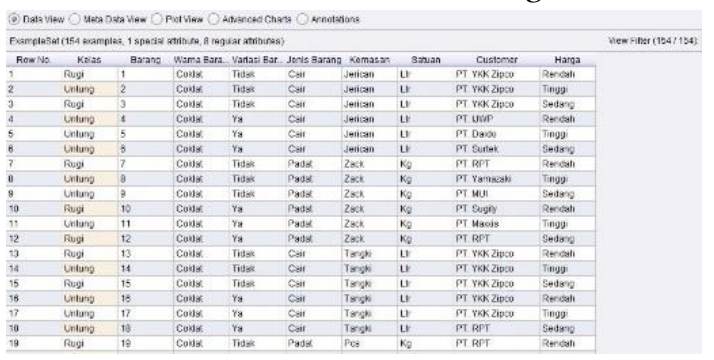

Tabel 3. Data Testing

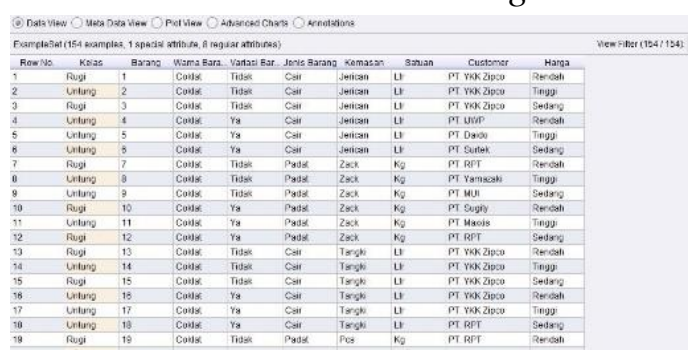

Berikut hasil pohon keputusan data training dan data testing.

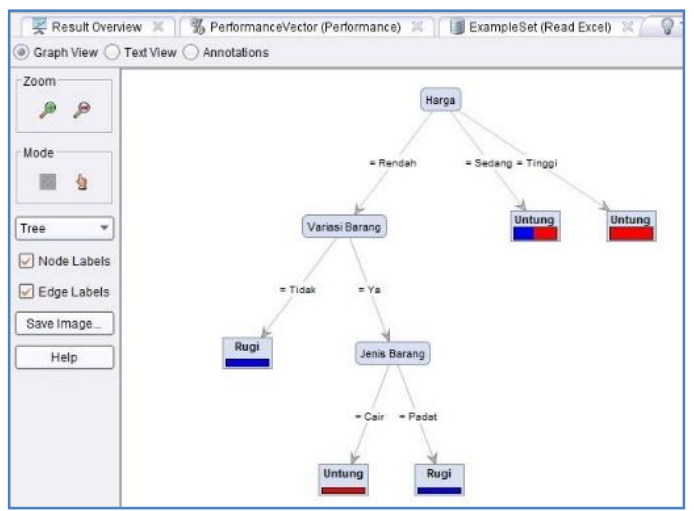

Gambar 2.Pohon Keputusan Data Training

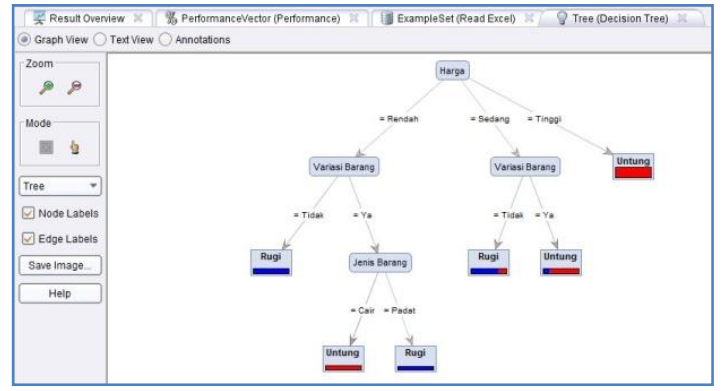

Gambar 3.Pohon Keputusan Data Testing 
Metode klasifikasi bisa dievaluasi berdasarkan kriteria seperti tingkat akurasi, kecepatan, kehandalan, stabilitas dan interpretabilitas (Vecellis, 2009). Lalu datanya diolah dan diuji tingkat akurasinya dengan metode Confussion Matrix dan kurva ROC/AUC (Area Under Cover).

\section{Confusion Matrix Data Training}

Perhitungan akurasi data training dari 154 data, 42 diklasifikasikan keuntungan ternyata true rugi, 7 data diprediksi true rugi tetapi ternyata true untung, 21 data diprediksi true rugi tetapi ternyata sebanyak 84 diprediksi sesuai true untung, dengan nilai accuracy sebesar $81,71 \%$.

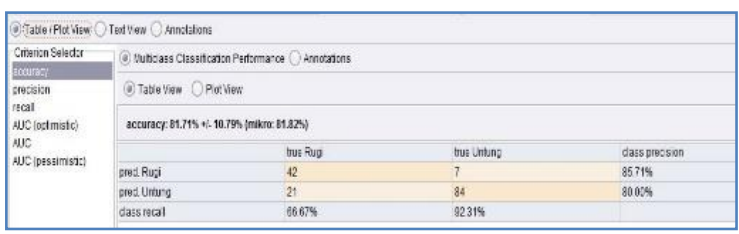

Gambar 4.Perhitungan Akurasi

Perhitungan akurasi berdasarkan precision, 42 diklasifikasikan keuntungan ternyata true rugi, 7 data diprediksi true rugi tetapi ternyata true untung, 21 data diprediksi true rugi tetapi ternyata sebanyak 84 diprediksi sesuai true untung, dengan nilai accuracy sebesar 83,20\%.

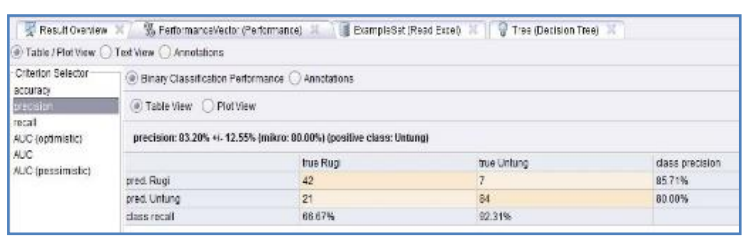

Gambar 5.Evaluasi Precision Data Training

Perhitungan akurasi berdasarkan recall, 42 diklasifikasikan keuntungan ternyata true rugi, 7 data diprediksi true rugi tetapi ternyata true untung, 21 data diprediksi true rugi tetapi ternyata sebanyak 84 diprediksi sesuai true untung, dengan nilai accuracy sebesar $91,81 \%$.

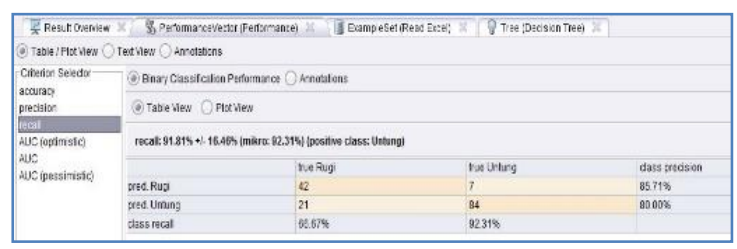

Gambar 6.Evaluasi Recall Data Training

Performance keakurasian AUC (Gorunescu, 2011) dapat diklasifikasikan menjadi lima kelompok yaitu:

1. $0.90-1.00=$ Excellent Clasification

2. $0.80-0.90=$ Good Clasification

3. $0.70-0.80=$ Fair Clasification

4. $0.60-0.70=$ Poor Clasification

5. $0.50-0.60=$ Failure

AUC Optimistic metode Algoritma C4.5 menggunakan data training sebesar 1,00 dengan tingkat akurasi kategori Excellent Clasification.

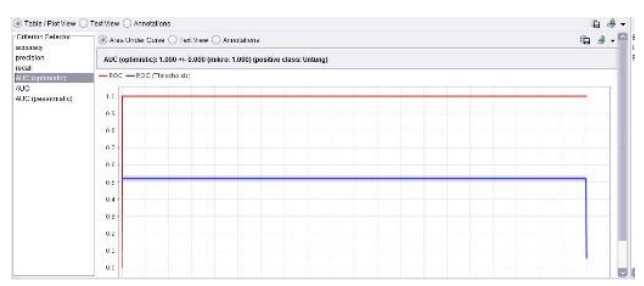

Gambar 7.Evaluasi AUC Optimistic

AUC Optimistic metode Algoritma C4.5 menggunakan data training sebesar 0,914 dengan tingkat akurasi kategori Excellent Clasification.

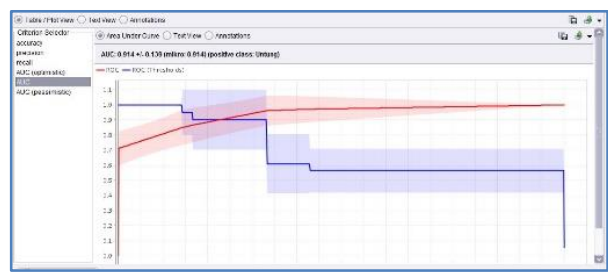

Gambar 8.Evaluasi AUC 
AUC Pessimistic metode Algoritma C4.5 menggunakan data training sebesar 0,879 dengan tingkat akurasi kategori Good Clasification.

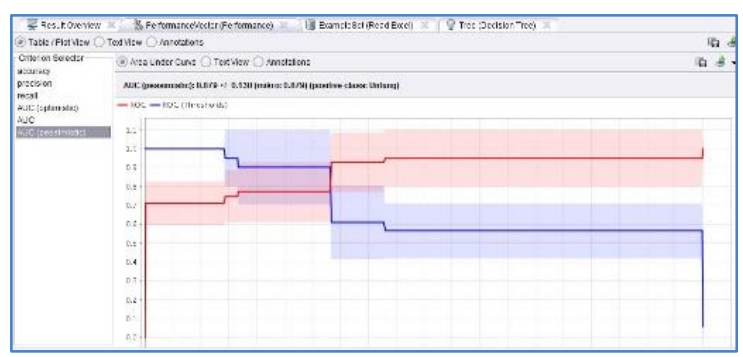

Gambar 9.Evaluasi AUC Pessimistic

\section{Confusion Matrix Data Testing}

Perhitungan akurasi data testing dari 38 data, 9 diklasifikasikan keuntungan ternyata true rugi, 1 data diprediksi true rugi tetapi ternyata true untung, 4 data diprediksi true rugi tetapi ternyata sebanyak 24 diprediksi sesuai true untung, dengan nilai accuracy sebesar $85,83 \%$.

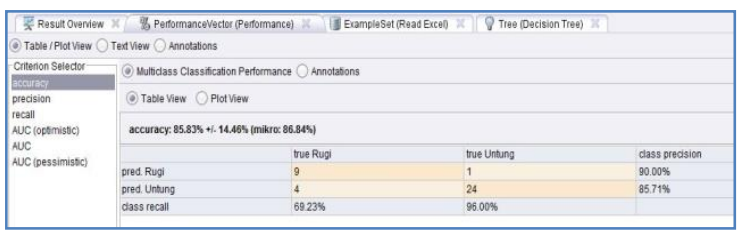

Gambar 10.Evaluasi Accuracy Data Testing

Perhitungan akurasi data testing dari 38 data, 9 diklasifikasikan keuntungan ternyata true rugi, 1 data diprediksi true rugi tetapi ternyata true untung, 4 data diprediksi true rugi tetapi ternyata sebanyak 24 diprediksi sesuai trueuntung, dengan nilai accuracy sebesar $85,83 \%$.

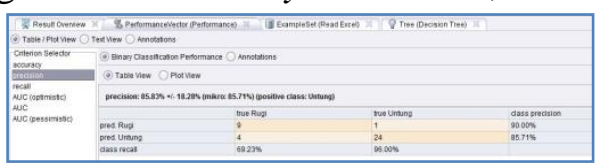

Gambar 11.Evaluasi Precission Data Testing
Perhitungan akurasi data testing dari 38 data, 9 diklasifikasikan keuntungan ternyata true rugi, 1 data diprediksi true rugi tetapi ternyata true untung, 4 data diprediksi true rugi tetapi ternyata sebanyak 24 diprediksi sesuai true untung, dengan nilai accuracy sebesar 95,00\%.

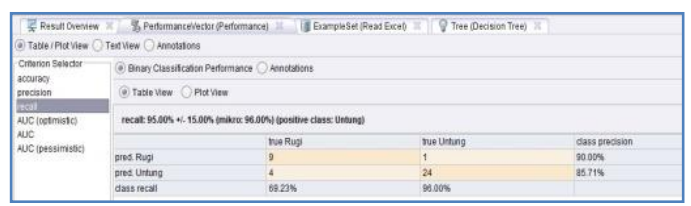

Gambar 12.Evaluasi Recall Data Testing

\section{ROC/AUC (Area Under Cover) Data} Testing

AUC Optimistic metode Algoritma C4.5 menggunakan data training sebesar 0,925 dengan tingkat akurasi kategori Excellent Clasification.

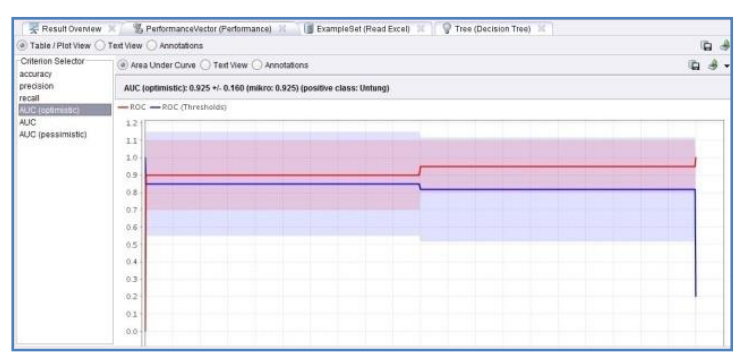

Gambar 13.Evaluasi AUC Optimistic

AUC metode Algoritma C4.5 menggunakan data training sebesar 0,550 dengan tingkat akurasi kategori Failure.

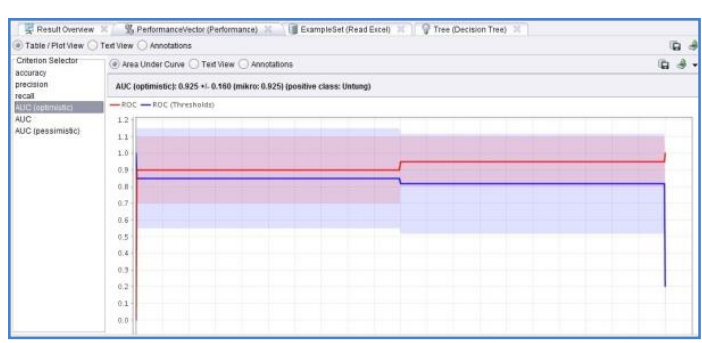

Gambar 14.Evaluasi AUC 
AUC metode Algoritma C4.5 menggunakan data training sebesar 0,700 dengan tingkat akurasi kategori Poor Clasification.

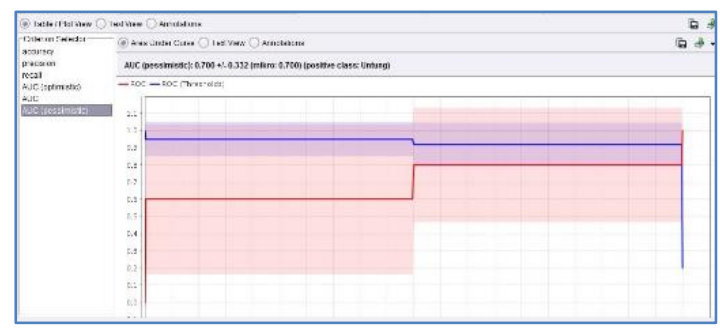

Gambar 15.Evaluasi AUC Pessimistic

\section{Accuracy Customer}

Hasil yang didapat dari pengolahan data training accuracy customer terlaris menggunakan metode Algoritma C4.5 sebesar 76,45\% yaitu pada PT. RPT (Resin Plating Technology) menggunakan data training.

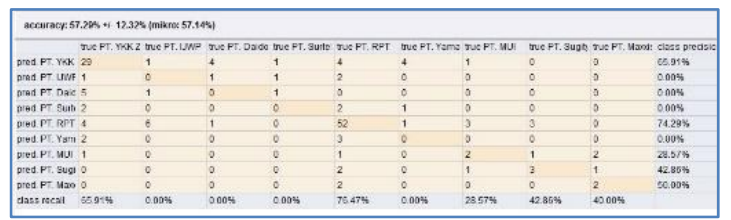

Gambar 16.Accuracy Customer

\section{KESIMPULAN DAN SARAN}

Berdasarkan tujuan penelitian dan hasil beserta pembahasan diperoleh kesimpulan bahwa hasil yang dicapai dari evaluasi hasil klasifikasi dalam prediksi keuntungan memiliki tingkat akurasi sebesar $81,71 \%$ dari data training dan tingkat akurasi sebesar $85,83 \%$ dari data testing dengan Confusion Matrix. Jika melihat dengan kurva ROC menggunakan data training dengan akurasi kategori Excellent Classification sebesar 1,000 dan data testing dengan akurasi kategori Excellent Classification sebesar 0,925.

\section{DAFTAR PUSTAKA}

Anggraini Sandrawira dkk. (2018). Analisis Data Mining Penjualan Ban Menggunakan Algoritma C4.5.Jurnal Ilmu Teknik Elektro Komputer dan Informatika (JITEKI)Vol. 4, No.2.

E. Buulolo, N. Silalahi, F. F and R. Rahim (2017). C4.5 Algorithm To Predict the Impact of the Earthquake. International Journal of Engineering Research \& Technology (IJERT), vol. 6 , no. 2 , pp. 10-15.

Gorunescu. (2011). Data Mining Concepts, Models and Techniques. Romania: Springer-Verlag Berlin Heidelberg.

Gunadi Goldiedkk (2012). Penerapan Metode Data Mining Market Basket Analysis Terhadap Data Penjualan Produk Buku DenganMenggunakan AlgoritmaApriori dan Frequent Pattern Growth (FP-Growth) Studi Kasus Percetakan PT. Gramedia. JurnalTelematika. Volume 4. Hal $118-132$.

Hermawati, Fajar Astuti. (2009).Algoritma Data Mining. Yogyakarta: Andi Offset.

Kamagi, D. H., \& Hansun, S. (2014). Implementasi Data Mining dengan Algoritma C4.5 untuk Memprediksi Tingkat Kelulusan Mahasiswa. ULTIMATICS, Vol. VI, No. 1 | Juni 2014, VI(1), 15-20.

Rika Nofitri, Muhammad Ardiansyah Sembiring(2017). Analisa Kinerja Algoritma C4.5 Dalam Memprediksi Pencapaian Profit. Seminar Nasional Multidisiplin Ilmu.

Vecellis, Carlo. (2009). Business Intelligence: Data Mining and Optimization for DecisionMaking. United Kingdom: John Willey \& Son 